\title{
Inclination of houses induced by liquefaction in the 2018 Hokkaido Iburi- tobu earthquake, Japan
}

\author{
Yuko Serikawa ${ }^{1 *}$, Masakatsu Miyajima' ${ }^{1}$ Masaho Yoshida ${ }^{2}$ and Kenji Matsuno ${ }^{1}$
}

\begin{abstract}
Background: On September 6th, 2018, at 3:07 local time, a strong earthquake of magnitude $M w=6.6$ struck the east Iburi region in Hokkaido, Japan. Many serious damages such as landslide, liquefaction and collapse of houses occurred from this earthquake. Liquefaction caused road deformation and inclination of houses in Sapporo city, Hokkaido. In order to understand the damage caused by the earthquake, and find a solution to mitigate the liquefaction-induced damage in Sapporo city, a preliminary investigation of the 2018 Hokkaido Iburi-tobu earthquake was conducted from 18 to 20 September 2018.

Results: The damages to the houses at Satozuka town and Utsukushigaoka town in Sapporo city are focused on. The damage at Satozuka was so enormous that the residents could not continue to live in their houses. Although the inclination of houses can be seen by visual inspection at Satozuka, there were few houses where the inclination can be judged visually at Utsukushigaoka. Therefore we did a field survey of inclined houses by using a digital angle meter at Utsukushigaoka.

Conclusions: The inclination of 57 houses at Utsukushigaoka was measured, and the maximum value and direction of inclination are shown on the map. The houses located at the reclaimed land of the former river and former valley plain were inclined. Therefore, the old terrain greatly affected to the inclination of houses. These liquefactioninduced damage occurred in the same area where liquefaction occurred during the 2003 Tokachi-oki earthquake.
\end{abstract}

Keywords: The 2018 Hokkaido Iburi-tobu earthquake, Liquefaction, Damage to houses, Inclination of house

\section{Background}

A big earthquake occurred and hit Hokkaido, Japan on September 6th, 2018. Many serious damages such as landslide, liquefaction and collapse of houses occurred by this earthquake. Liquefaction caused road deformation and inclination of houses in Sapporo city, Hokkaido. Many roads were inaccessible, and operation of emergency vehicle was affected by the ground deformation directly after the event. Inclination of houses also caused health problems for the residents. Therefore, these damages were serious problems in Sapporo city, Hokkaido.

We conducted field surveys such as measurement of inclination and interview to the residents of 57 houses at Utsukushigaoka, Kiyota ward, Sapporo city in this

\footnotetext{
* Correspondence: bunka.h22@gmail.com

${ }^{1}$ Kanazawa University, Kakuma-Machi, Kanazawa City, Ishikawa Prefecture 920

1192, Japan

Full list of author information is available at the end of the article
}

research. The direction and angle of inclination of the houses are shown on the map, and the map is compared to the old topographical map and liquefaction history of past earthquakes. Then, we discuss the mechanism of inclination of houses by liquefaction.

\section{Methodologies and findings \\ Outline of earthquake damage}

An earthquake of about $35 \mathrm{~km}$ depth and Magnitude 6.7 occurred middle east of Hokkaido-iburi region at AM 3: 07 local time on September 6th, 2018. Figure 1 shows a distribution of JMA (Japan Meteorological Agency 2018) seismic intensity. A maximum JMA seismic intensity of 7 was observed at Atsuma town. The human damage of this earthquake was 42 deaths, 31 seriously injured and 731 minor injuries. Table 1 lists an outline of the damage caused by this earthquake (Cabinet Office 2018). The damage to houses and buildings were 462 completely destroyed 


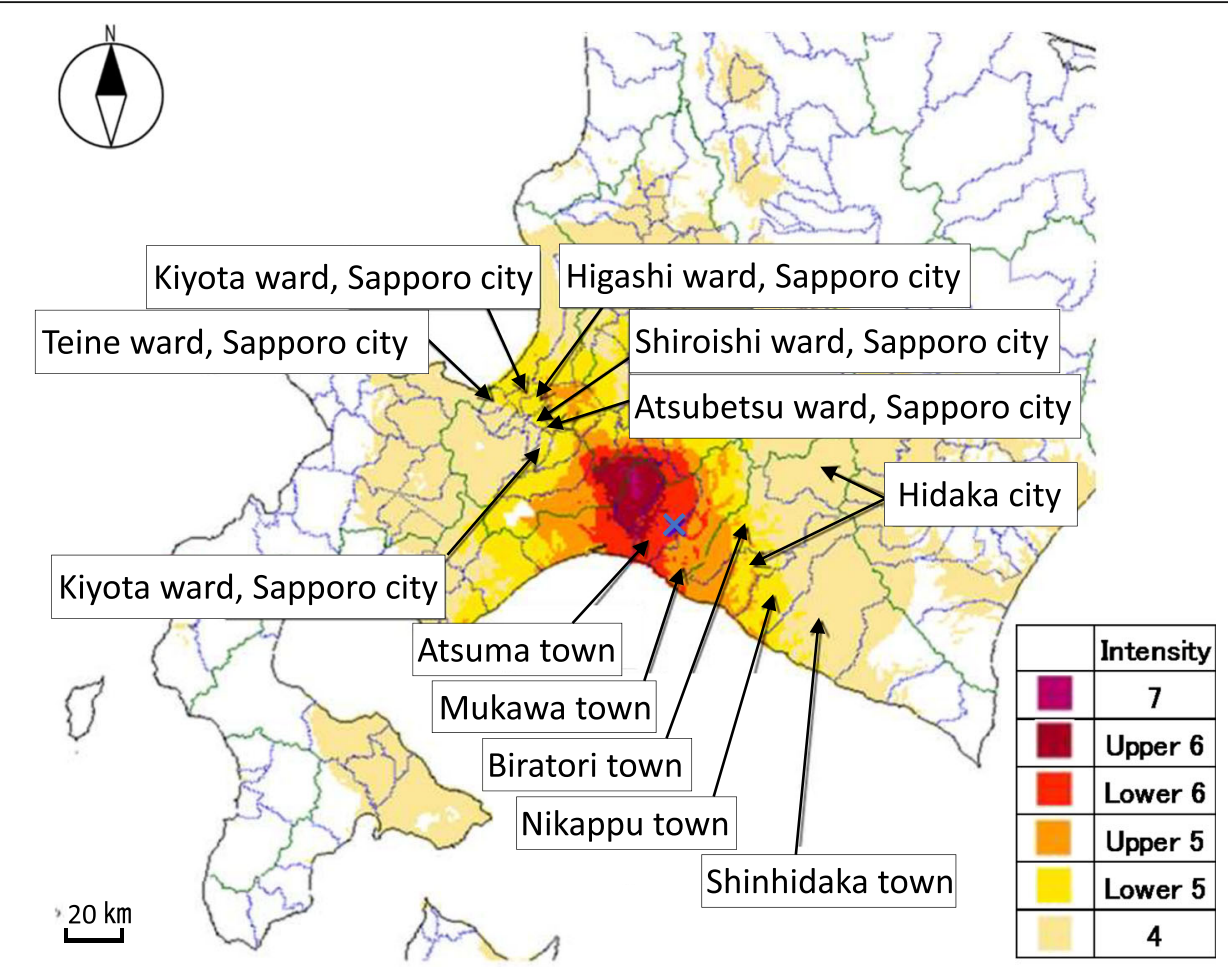

Fig. 1 Seismic intensity distribution of the 2018 Hokkaido Iburi-tobu Earthquake (Japan Meteorological Agency 2018)

houses, 1570 partially destroyed and 12,600 slightly damaged houses. Two thousand four hundred fifty-six nonresidential buildings were also damaged. The main cause of these damages were landslides at Atsuma near the epicenter. Fig. 2 shows the landslide that occurred at Atsuma. The total area of landslides was about $13.4 \mathrm{~km}^{2}$ according to the Ministry of Land, Infrastructure and Transport, Japan. This scale is the biggest in Japan since 1968. One of causes of the landslides seems to be a large amount of water contained in soil because of heavy rain caused by a strong typhoon the previous day. It is considered that the descent pumice layer deposited in this area is highly permeable, and clay is formed by chemical weathering, therefore, landslides are likely to occur.

Table 1 (a) The Human damage caused by the earthquake. (b) The houses and buildings damage caused by the earthquake (Cabinet Office 2018)

\begin{tabular}{|c|c|c|c|}
\hline \multicolumn{4}{|c|}{ The human damage (person) } \\
\hline Deaths & Seriously injures & Minor injuries & \\
\hline 42 & 31 & 731 & \\
\hline \multicolumn{4}{|c|}{ The damage to houses and bildings (building) } \\
\hline $\begin{array}{l}\text { Completely } \\
\text { destroyed }\end{array}$ & Semi-damage & $\begin{array}{l}\text { Partially } \\
\text { damaged }\end{array}$ & Non-residential \\
\hline 462 & 1,570 & 12,600 & 2,456 \\
\hline
\end{tabular}

Liquefaction occurred in some areas. Uplift and sinking of road and inclination of houses were caused by liquefaction in the part of southeastern Sapporo city. Enormous liquefaction-induced damage occurred in a wide area of Satozuka and Utsukushigaoka, Kiyota ward, Sapporo city. The present study focuses on the damage to houses induced by liquefaction.

Furthermore, all power plants in Hokkaido stopped, and a massive power outage of 2.95 million households occurred. The blackout was completely eliminated on October 4th. Water supply also stopped in Sapporo city and some towns. Water stop continued at Atsuma for more than 1 month.

\section{Liquefaction in Kiyota ward, Sapporo city}

Uplift and sinking of road and inclination of houses were caused by liquefaction in the part of southeastern Sapporo city, where hilly land consisting of pyroclastic flow sediment of Shikotsu volcano. Enormous liquefaction damage occurred in a wide area of Satozuka and Utsukushigaoka, Kiyota ward, Sapporo city. Fig. 3 shows the location of Satozuka and Ustukushigaoka. Some photographs of the damage at each site are shown in Fig. 3. The ground deformation due to liquefaction was the largest and the ground was settled down about $2.0 \mathrm{~m}$ at Satozuka 1 jo (Wakamatsu and Onoue 2018) shown as yellow portion in Fig. 4. Figure 4-(1)shows settlement of the ground and 


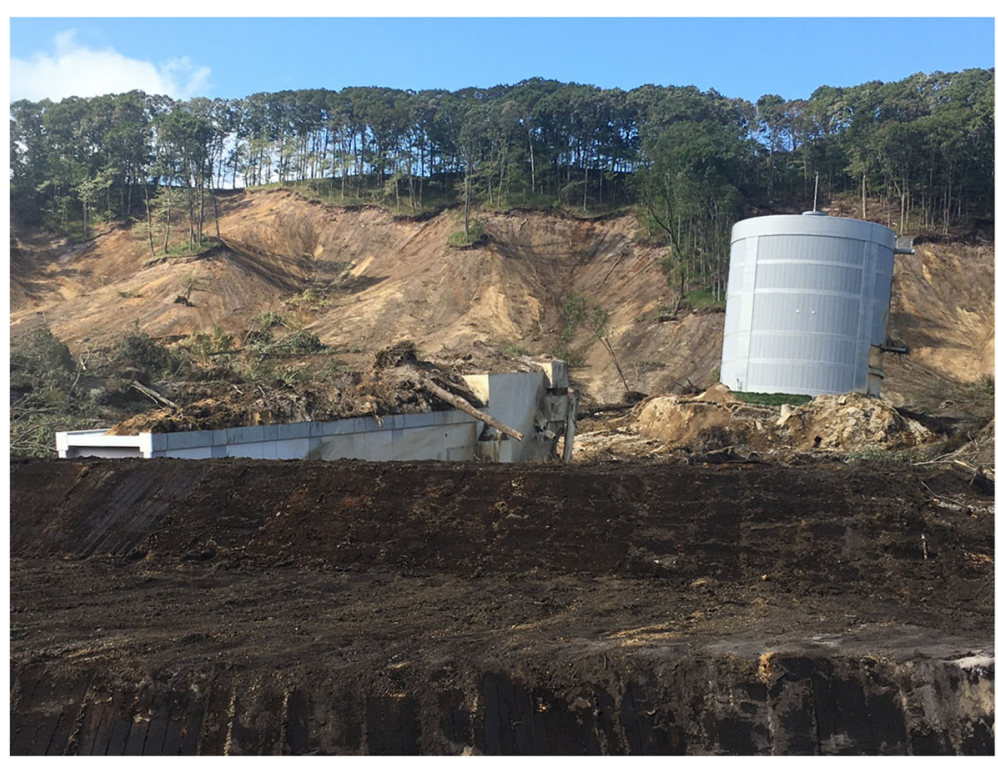

Fig. 2 Landslide at Atsuma town

inclination of the houses are remarkable and water puddles formed in front of the house. The road shown in Fig. 4-(2) collapsed, and traffic using vehicles was difficult. Since the ground level before the earthquake was at the top of this utility hole in Fig. 4-(3), it is considered that this road subsided about $1.2 \mathrm{~m}$.
The inclination of the surrounding houses was large. Figure 4-(4) shows accumulated sand in height of about $1.3 \mathrm{~m}$. It is thought that a large amount of liquefied sand ejected at the sites of Fig. 4-(1) to (3) was accumulated at the location of Fig. 4-(4) because the location of Fig. 4-(4) is lower than the sites of Fig.

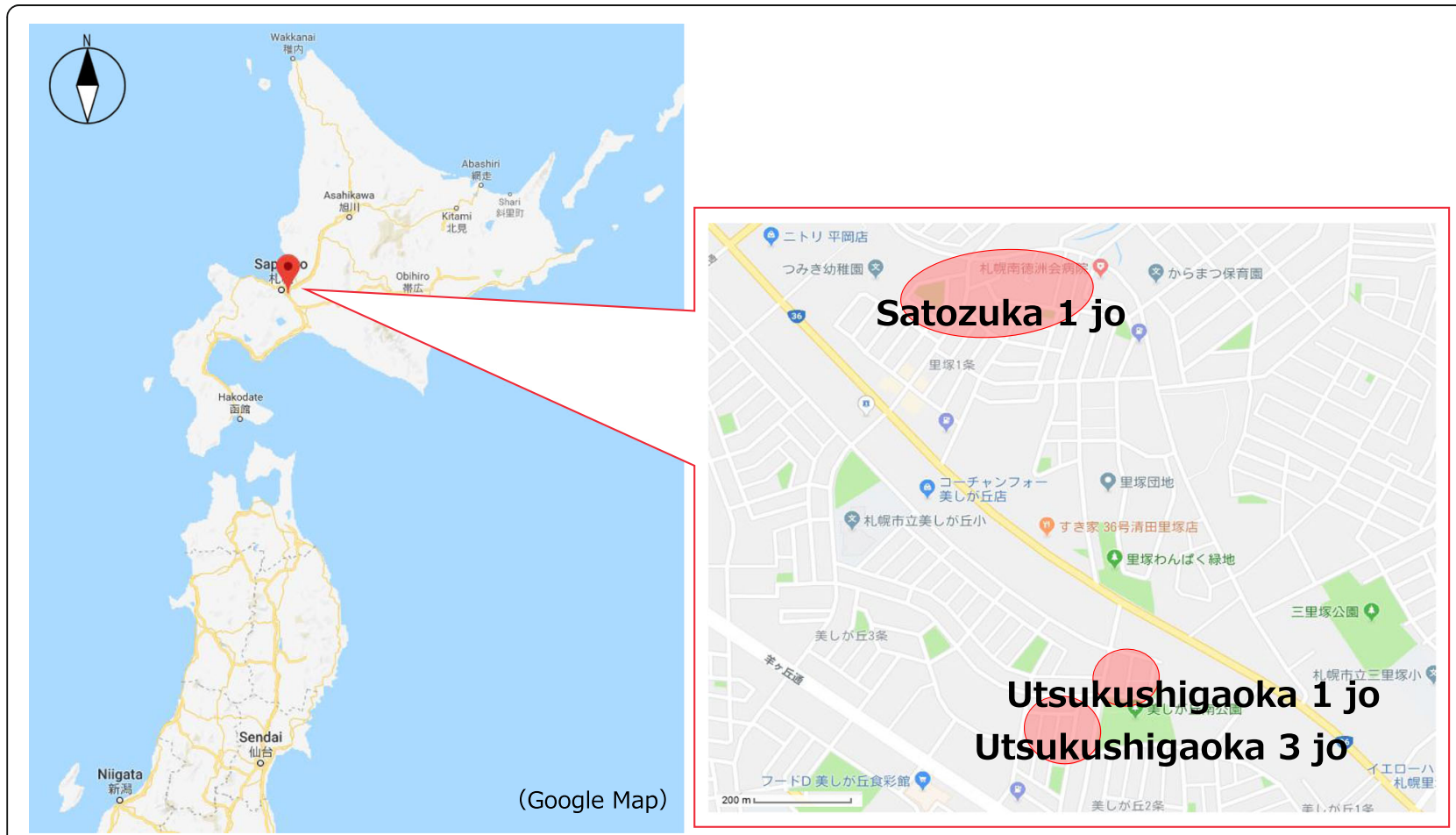

Fig. 3 Survey area 


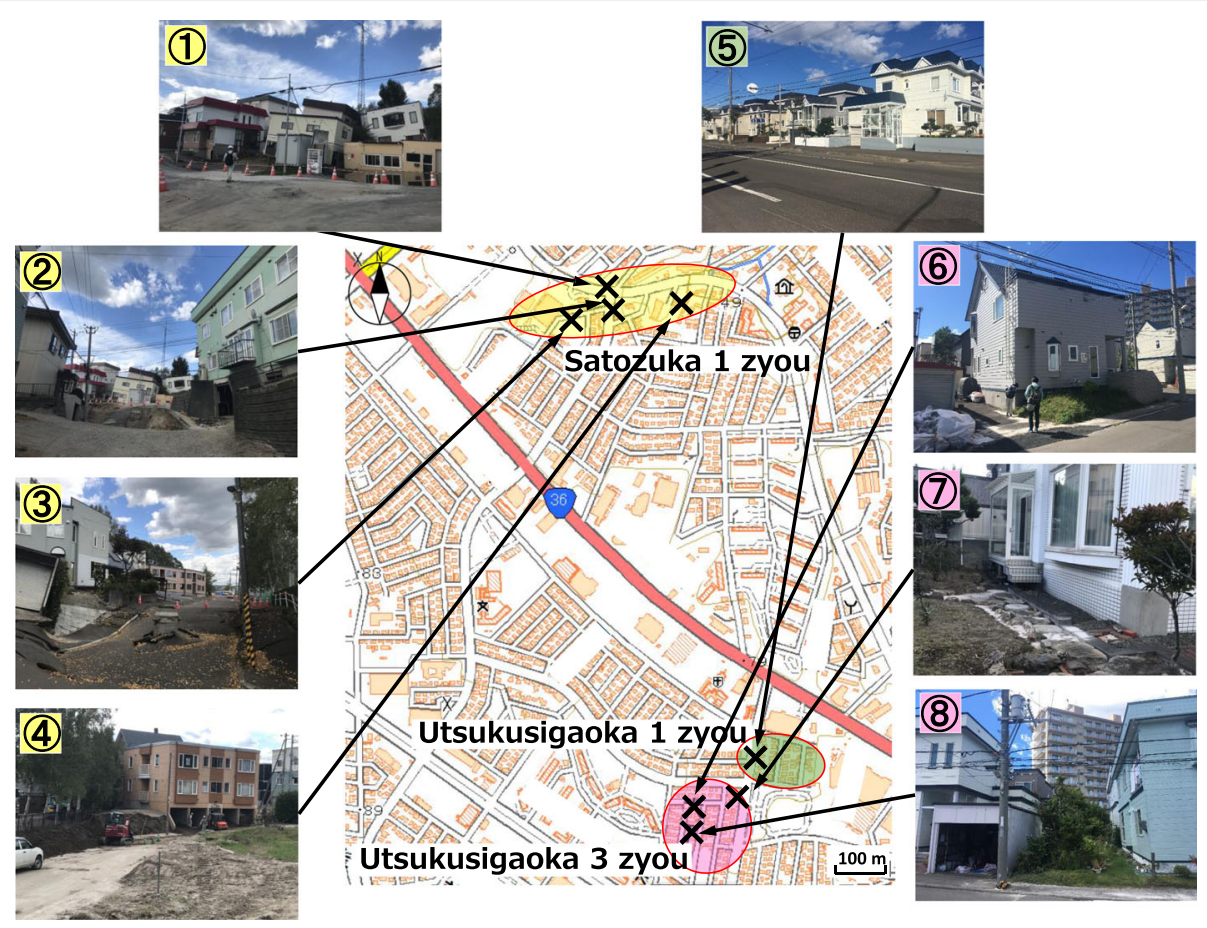

Fig. 4 Liquefaction-induced damage at each point

4-(1) to (3). In this area, tension cracking was not seen so much, so it can be inferred that the lateral spreading is not large.

The green portion in Fig. 4 indicates Utsukushigaoka 1 jo. There were many inclined houses due to liquefaction. The houses shown in Fig. 4-(5) seems to suffer no damage at first glance, but inclination of houses occurred. Most of the residents continued to live at the inclined houses just after the earthquake, but many residents moved without being able to withstand the inclination of houses after around 1 month.

The red portion in Fig. 4 indicates Utsukushigaoka 3 jo. Many houses suffered inclination by liquefaction. The inclination of the house shown in Fig. 4-(6) was the second largest inclination in Utsukushigaoka. The residents of this house moved soon after the earthquake. The surrounding ground of the house shown in Fig. 4-(7) subsided, and there was a gap between the stairs and the ground. The inclined houses shown in Fig. 4-(8) were inclined to the direction of each house. The right house was with the largest inclination in the Utsukushigaoka. The utility pole shown in this photo has settled about $1.8 \mathrm{~m}$ (Wakamatsu and Onoue 2018).

Although the inclination of houses can be seen by visual inspection at Satozuka, there were few houses where the inclination can be judged visually at Utsukushigaoka. Therefore we did a field survey of inclined houses by using a digital angle meter in Utsukushigaoka.
Investigation of inclination of houses by liquefaction Overview of field survey

Utsukushigaoka, Kiyota ward, Sapporo city was selected as a target area in this research because the inclination of houses caused a serious health problems of the residents and the liquefaction also occurred in the past earthquake. The maximum JMA seismic intensity of Utsukushigaoka 1 jo and 3jo was $5^{+}$and the maximum horizontal acceleration at the strong motion station (K-NET HKD 182) closest to the Utsukushigaoka was 205.8 gal.

The field survey was conducted on September 19th and 20th, about 2 weeks after the earthquake. The survey was conducted by using a "Neoteck Digital Angle Meter" to measure the inclination of the four outer walls of each house.

\section{Results of measurements}

Figure 5 shows inclination of the outer wall of the houses in Utsukushigaoka 1 jo and 3 jo. The inclination is shown in color-coded of every 0.25 degree on the map. Vector synthesis was performed in two orthogonal directions and the direction of inclination with larger inclination is indicated by an arrow in this figure. If the maximum inclination and the synthesized inclination are less than 0.25 degree, vector synthesis is not performed and only the direction of the maximum inclination is shown. The location of largest subsidece of road is also indicated by red cross in this figure. It is found that the houses that were greatly inclined were adjacent and that 


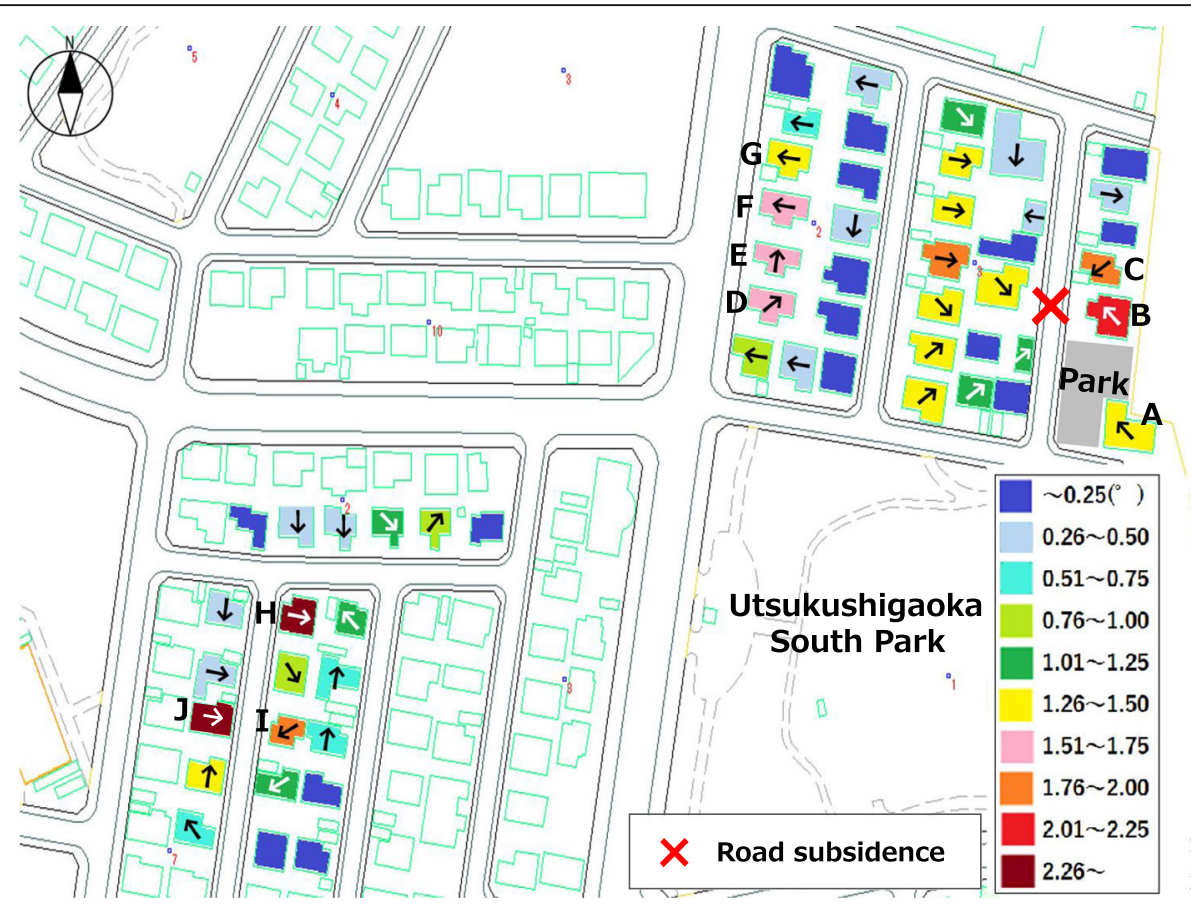

Fig. 5 Magnitude and direction of inclination of houses

such houses are inclined in the same direction according to Fig. 5. The houses were also inclined in the direction of the largest subsided road. These houses have almost the same wooden structure and were constructed 29 years ago.

The houses in the vicinity of the subsided road, houses A to $\mathbf{C}$ are listed in Table 2. These houses with large inclination are located near the park (Utsukushigaoka Sumire Park) where many sand volcanoes appeared by liquefaction. The houses $\mathbf{B}$ and $\mathbf{C}$ were greatly inclined in the direction of the subsided road. The inclined houses located along the main street are listed in Table 3. Houses $\mathbf{D}$ and $\mathbf{E}$ were inclined in the north direction, Houses $\mathbf{F}$ and $\mathbf{G}$ were inclined to the west direction. The houses where the inclination were great in Utsukushigaoka 3 jo are listed in Table 4. The inclination of the outer wall of the house $\mathbf{J}$ was 2.58 degree, which was the largest inclination among the surveyed houses. The second largest inclination house $\mathbf{H}$ was inclined 2.40 degree. Houses $\mathbf{H}$ and $\mathbf{J}$ were inclined to the southeast direction, and house I was inclined in the southwest direction. The houses $\mathbf{J}$ and $\mathbf{I}$ were inclined to the front road. These results revealed that most of the large inclined houses inclined to the same direction.

The number of houses in each inclination angle is shown in Fig. 6. Kohiyama and others conducted a hearing survey on health problems for residents who suffered liquefaction damage during The 2011 Tohoku earthquake, and dizziness gradually occurred when the inclination angle exceeded 1/100 (0.6 degree), revealed that health problems occur. Health problems may occurred at the houses with an inclination of 0.6 degree or more

Table 2 Inclination of houses (Utsukushigaoka 1jo, A to C)

\begin{tabular}{|c|c|c|c|c|}
\hline House & & A & B & $C$ \\
\hline \multicolumn{5}{|l|}{ Picture } \\
\hline \multirow[t]{3}{*}{ Inclination } & Outer wall & $1.99^{\circ}$ northwest & $2.25^{\circ}$ northwest & $1.54^{\circ}$ southwest \\
\hline & Inner wall & - & - & $1.35^{\circ}$ \\
\hline & Floor & - & - & $1.93^{\circ}$ \\
\hline
\end{tabular}


Table 3 Inclination of houses (Utsukushigaoka 1jo, D to G)

\begin{tabular}{|c|c|c|c|c|c|}
\hline House & & D & $E$ & $\mathrm{~F}$ & G \\
\hline \multicolumn{6}{|l|}{ Picture } \\
\hline \multirow[t]{3}{*}{ Inclination } & Outer wall & $1.86^{\circ}$ northeast & $1.57^{\circ}$ north & $1.72^{\circ}$ west & $1.32^{\circ}$ west \\
\hline & Inner wall & $1.72^{\circ}$ & $2.12^{\circ}$ & $2.31^{\circ}$ & $1.83^{\circ}$ \\
\hline & Floor & $2.20^{\circ}$ & $1.94^{\circ}$ & $2.22^{\circ}$ & $2.14^{\circ}$ \\
\hline
\end{tabular}

(Kohiyama et al. 2012), and about 53\% of the surveyed houses exceeded it. Survey of inclination of houses was conducted again 1 month after the earthquake. Inclination of houses increased more than 1.8 degrees in some cases by the aftershocks. There were two aftershocks that exceeded JMA seismic intensity 5 between our first and second field survey, and there were houses with large inclinations due to this aftershock. It was difficult for the residents to live there and most of decided to move. Since there are many residents who have difficulties in living, it is thought that the impact of inclination of houses caused by liquefaction on resident's quality of life very serious.

\section{Discussion}

Hokkaido has frequently suffered damages induced by liquefaction, such as in the 1952 Tokachi-oki, the 1993 Kushiro-oki, the 2003 Tokachi-oki earthquakes. The enormous liquefaction damage caused by the 2003 Tokachi-oki earthquake in Sapporo city. The liquefaction in the 2018 Hokkaido Iburi-tobu earthquake is compared with that in the 2003 Tokachi-oki earthquake here.

Figure 7 shows areas of ground deformation and inclination of houses in the 2003 Tokachi-oki earthquake according to reconnaissance report of the Japanese Geotechnical Society (The Japanese Geotechnical Society
2018). The surveyed area and the houses with an inclination of 0.51 degree or more in the present study are also indicated in this figure. This figure reveals that liquefaction-induced damages in both earthquakes occurred in the vicinity of the former river, and the damage area in the 2018 Hokkaido Iburi-tobu earthquake is considered to be more extensive than that in the 2003 Tokachi-oki earthquake.

Figure 8 shows an old topographical map of Kiyota ward, Sapporo city in 1961(Geographical Survey Institute 2018). According to this map, Utsukushigaoka was valley. Figure 9 is superimposed the past terrain on Fig. 5. According to this figure, the houses built in the former valley were inclined. It can be seen that houses A, B and C with large inclination and largely settled road were located at the former valley. Houses $\mathbf{D}$ and $\mathbf{E}$ were inclined in the direction of north and houses $\mathbf{F}$ and $\mathbf{G}$ in the west direction. These areas were formerly flood or valley plain. Houses $\mathbf{H}, \mathbf{I}$ and $\mathbf{J}$ are also located at the former valley. It is clear that the direction of inclination of the houses coincides with the direction of former valley or flood plain.

The surveyed areas of this study was originally recessed areas that erodes mountains, plateaus and terrace, then the area was reclaimed for residential houses in 1965. Houses $\mathbf{D}$ to $\mathbf{F}$ and $\mathbf{G}$ were located at the former flood and valley plains, houses $\mathbf{A}$ to $\mathbf{C}$ and $\mathbf{H}$ to $\mathbf{J}$

Table 4 Inclination of houses (Utsukushigaoka 3jo, H to J)

\begin{tabular}{llll}
\hline House & \\
\hline Picture & \\
Inclination & Outer wall \\
Inner wall & Floor & $2.40^{\circ}$ east & $2.10^{\circ}$ southwest \\
\hline
\end{tabular}




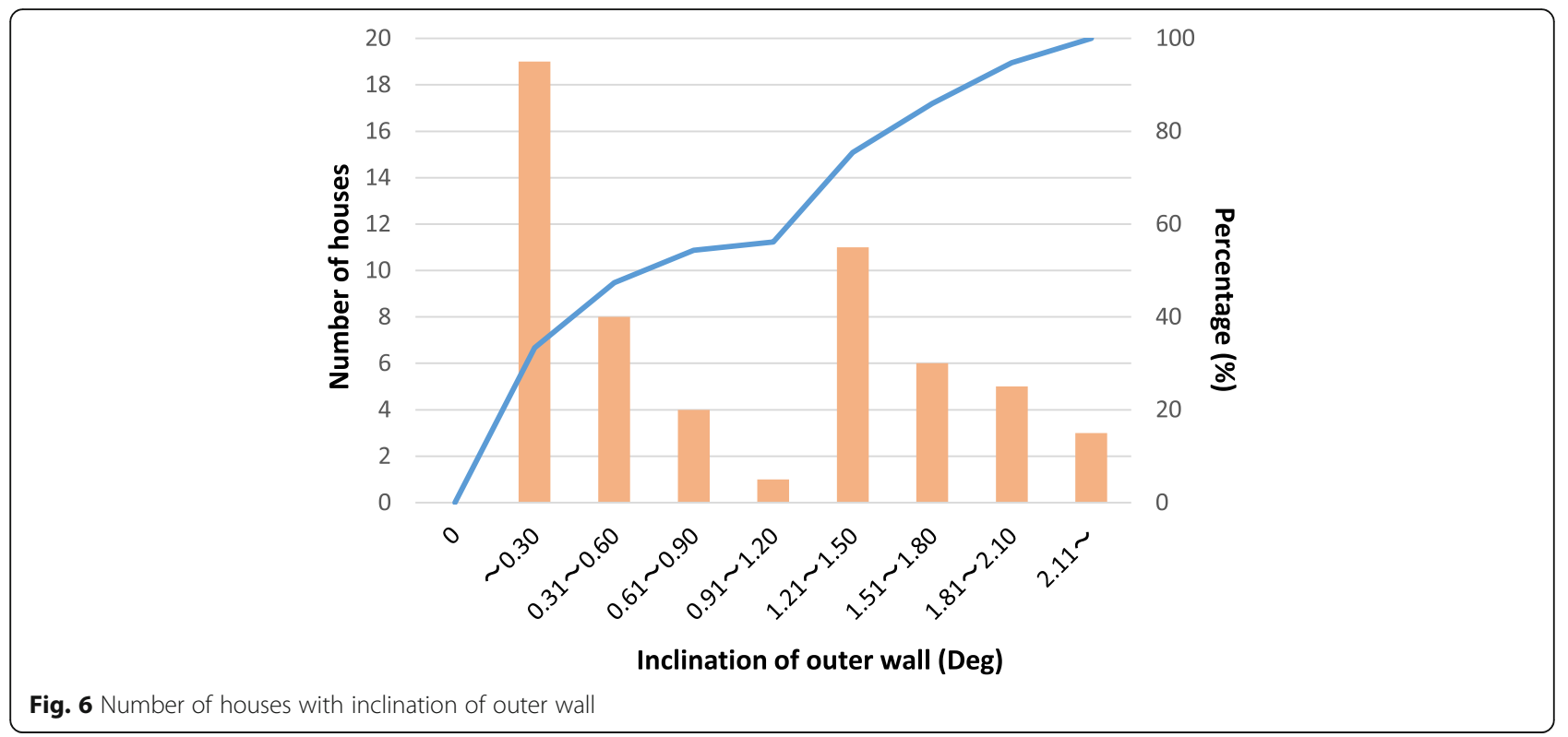

were located at the former bottom of valley plains. It was revealed that the inclination damage of houses due to liquefaction is greatly affected by the old topography. According to a survey of the Civil Engineering Research Institute for Cold Region, it is known that the survey target site is about $3 \mathrm{~m}$ of filled volcanic ash and the groundwater level is about $1 \mathrm{~m}$. The groundwater is very shallow and it is considered that the ground is a high possibility of liquefaction.

\section{Conclusion}

The present study introduced the damage to houses induced by liquefaction in the 2018 Hokkaido Iburi-tobu earthquake. The damages to the houses at Satozuka and

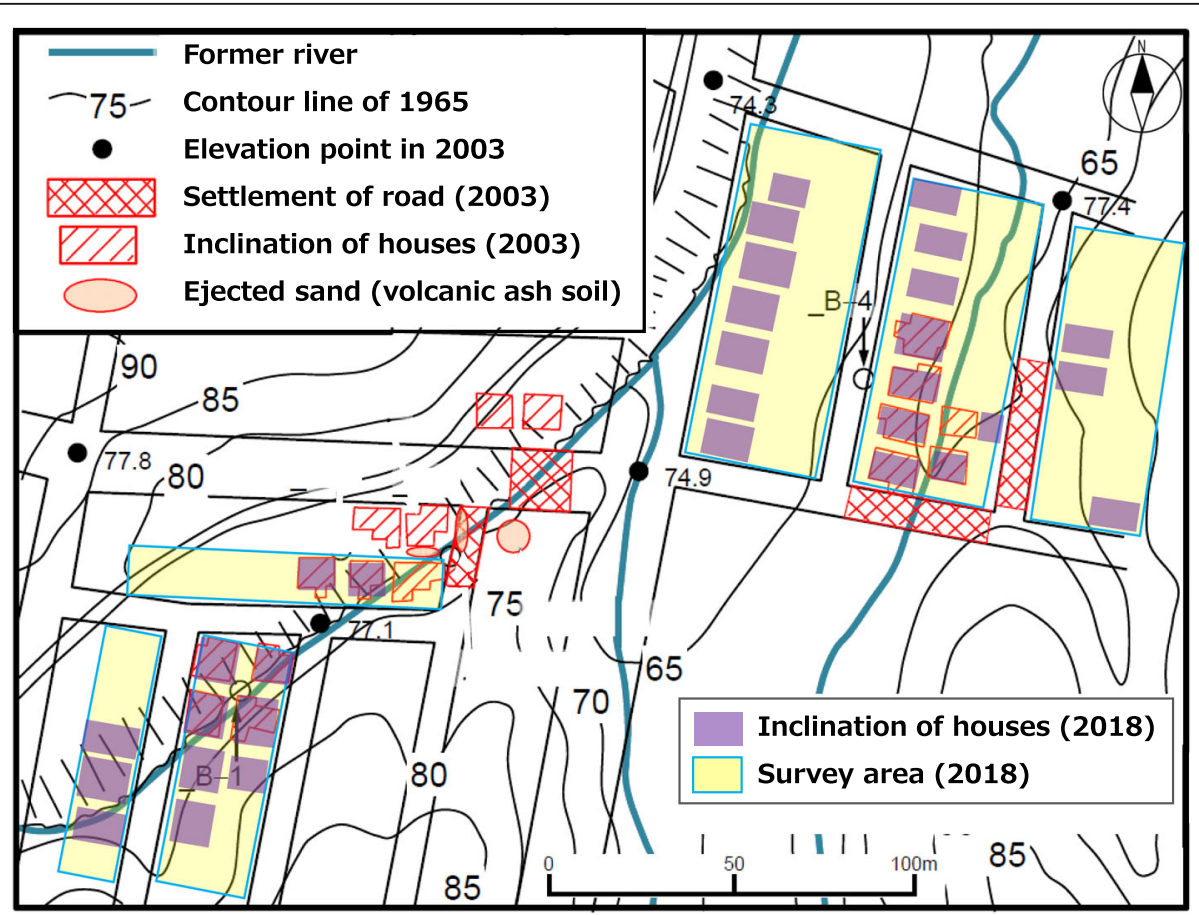

Fig. 7 Inclination of houses in the 2003 Tokachi-oki earthquake and the 2018 Hokkaido Iburi-tobu earthquake (The Japanese Geotechnical Society 2018) 


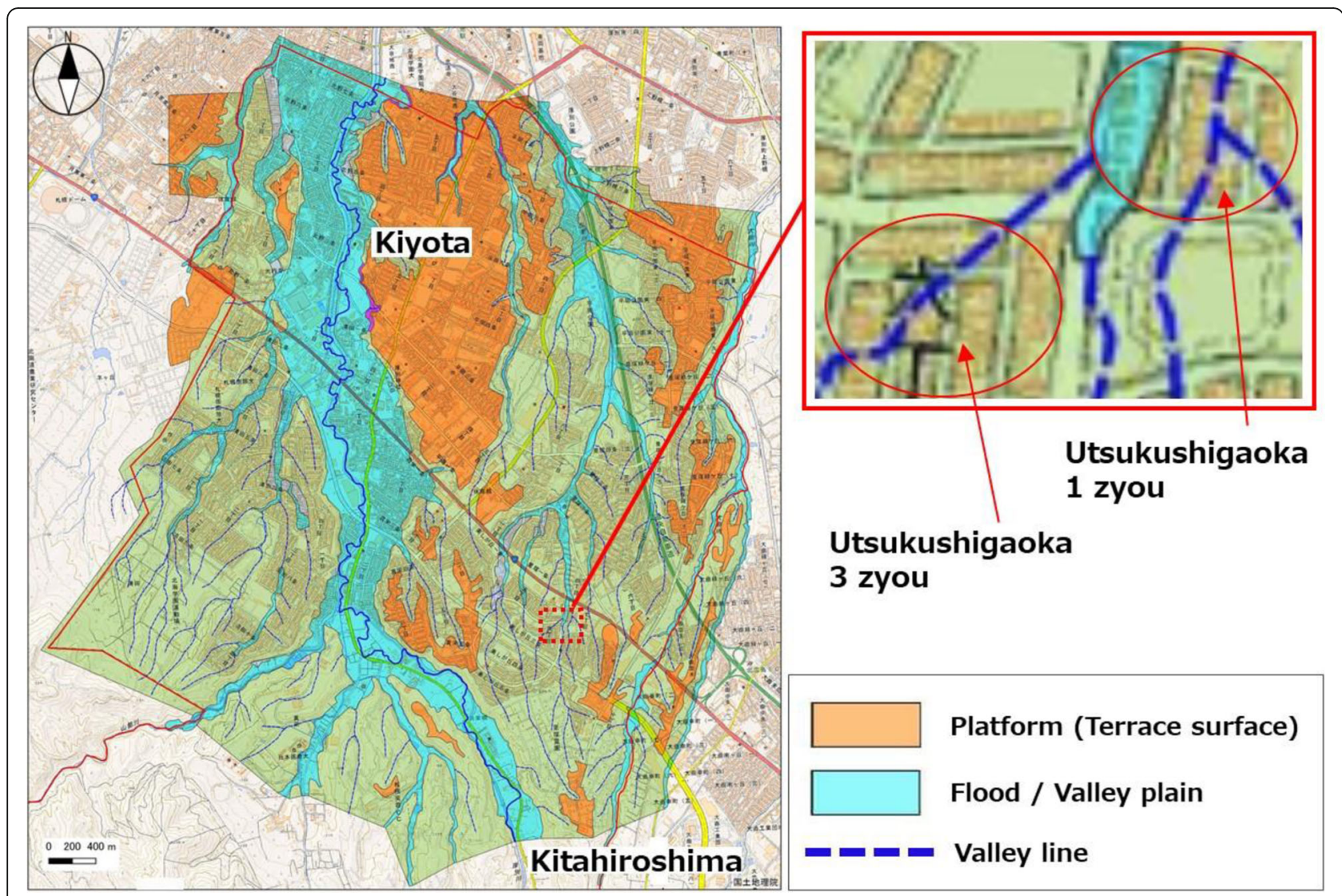

Fig. 8 The old topographical map of Kiyota ward, Sapporo city in 1961(Geographical Survey Institute 2018)

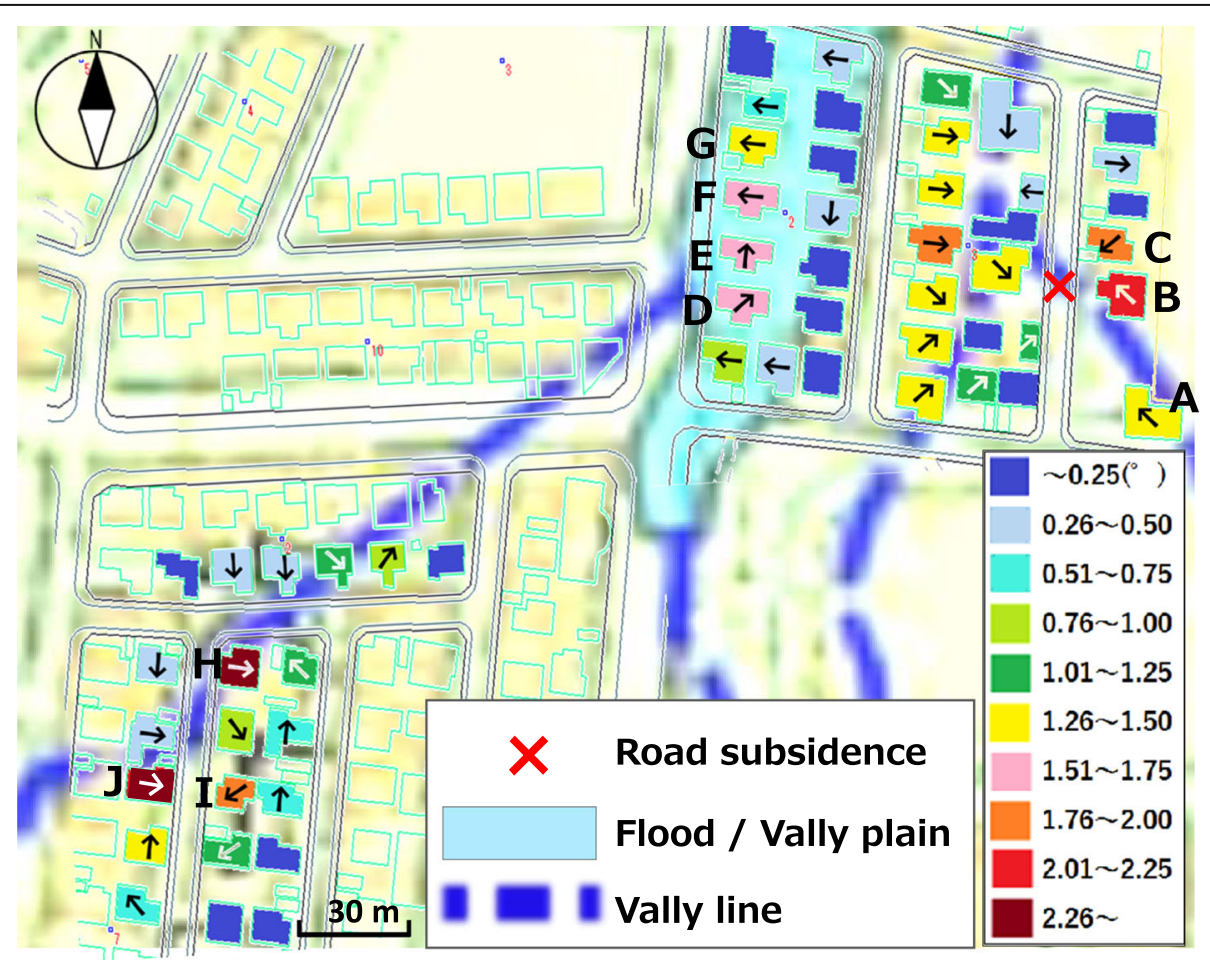

Fig. 9 Superposition of outer wall slope and former terrain 
Utsukushigaoka in Sapporo city are focused. The damage at Satozuka was so serious that the residents could not continue to live there. Although the inclination of houses can be seen by visual inspection at Satozuka, there were few houses where the inclination can be judged visually at Utsukushigaoka. Terefore we did a field survey of inclined houses by using a digital angle meter in Utsukushigaoka.

The inclination of 57 houses at Utsukushigaoka, Sapporo city was measured, and the maximum value and inclination direction were shown on the map. The houses located at the reclaimed land of the former river and former valley plain were inclined. Therefore, the old terrain greatly affected the inclination of houses. These liquefactions induced damage occurred at the same area of liquefaction occurred in the 2003 Tokachi-oki earthquake.

Health problems may occurr at houses with an inclination of 0.6 degree or more, and about $53 \%$ of the surveyed houses exceeded this. Survey of inclination of houses was conducted again 1 month after the earthquake. Inclination of houses increased more than 1.8 degree in some cases by the aftershocks. The residents found living there difficult and most of residents decided to move. Therefore, it is considered that countermeasures to liquefaction of detached houses are necessary because liquefaction induced damage to houses has a great influence on the health of residents. Since liquefaction measures for houses are not widely used at present, in areas where there is a high risk of liquefaction, it is necessary to take measures to reduce such inclination damage.

\section{Acknowledgments}

This work was supported by JSPS KAKENHI Grant Numbers $18 \mathrm{H} 01677$ and $18 \mathrm{J11630}$. All members of the reconnaissance team are much indebted and thankful to the residents of Kiyota ward, Sapporo city, for their kind supports to the survey activities in the stricken areas. Lastly all the members would like to express hereby their sympathy to the people affected by the devastating earthquake.

\section{Authors' contributions}

YS, MM, MY and KM participated in the field investigation. YS and MM drafted the manuscript. All authors have read and approved the final manuscript.

\section{Funding}

This work was financially supported by JSPS KAKENHI Grant Numbers $18 \mathrm{H} 01677$ and $18 \mathrm{~J} 11630$.

\section{Availability of data and materials}

Not applicable

\section{Competing interests}

The authors declare that they have no competing interests.

\section{Author details}

'Kanazawa University, Kakuma-Machi, Kanazawa City, Ishikawa Prefecture 920 1192, Japan. ${ }^{2}$ National Institute of Technology, Fukui College, Geshi, Sabae City, Fukui Prefecture 916-8507, Japan.
Received: 11 April 2019 Accepted: 2 September 2019

Published online: 04 November 2019

\section{References}

Cabinet Office (2018), About the damage situation to affect the 2018 Hokkaido Iburi-tobu earthquake, Japan, http://www.bousai.go.jp/updates/h30jishin hokkaido/pdf/310128_jishin_hokkaido.pdf (last visit: 30 Jan. 2019).

Geographical Survey Institute (2018), The old topographical map of Kiyota ward, Sapporo city in 1961, http://www.gsi.go.jp/common/000205584.pdf (last visit: 26 Nov. 2018).

Japan Meteorological Agency. 2018. About the "the 2018 Hokkaido Iburi-tobu earthquake, Japan". Vol. 6 https://www.jma.go.jp/jma/press/1809/07c/ kaisetsu201809071600.pdf (last visit: 30 Jan. 2019.

Kohiyama, M., C. Keino, and T. Sonabe. 2012. Questionnaire survey on health disturbance of residents in mihama ward, Chiba City who suffered housing damage due to liquefaction. Journal of Social Safety Science (17): p. 1. http:// isss.jp.net/isss-site/wp-content/uploads/2013/08/2012-016_cd.pdf. (last visit: 26 Nov. 2018).

The Japanese Geotechnical Society (2018), Recconnaissance team of geotechnical disasters in the 2018 Hokkaido Iburi-tobu earthquake, liquefaction damage due to the 2018 Hokkaido Iburi-tobu earthquake, Japan, https://www.jiban.or.jp/wp-content/uploads/2018/10/nishimura_watabe_201 81002.pdf (last visit: 26 Nov. 2018).

Wakamatsu, K., Onoue, A. (2018), Geotechnical disasters in Utsukushigaoka, Kiyota ward, Sapporo City in the 2018 Hokkaido Iburi-tobu Earthquak, http://www. koa-kaihatsu.co.jp/wp-content/uploads/2018/09/utsukushigaoka_kiyota_ report\%E8\%88\%88\%E4\%BA\%9CHP.pdf (last visit: 26 Nov. 2018).

\section{Publisher's Note}

Springer Nature remains neutral with regard to jurisdictional claims in published maps and institutional affiliations.

\section{Submit your manuscript to a SpringerOpen ${ }^{\circ}$ journal and benefit from:}

- Convenient online submission

- Rigorous peer review

- Open access: articles freely available online

High visibility within the field

- Retaining the copyright to your article

Submit your next manuscript at $\boldsymbol{\nabla}$ springeropen.com 